\title{
EDITORIAL
}

\section{The genetic etiology of systemic lupus erythematosus: a short dispatch from the combat zone}

\author{
JB Harley \\ Department of Medicine, University of Oklahoma, Oklahoma Medical Research Foundation, US Department of Veterans Affairs \\ Medical Center, Oklahoma City, OK, USA
}

Genes and Immunity (2002) 3 (Suppl 1), S1-S4. doi:10.1038/sj.gene.6363908

Keywords: SLE; lupus; genetics; review; linkage

In the last moment of peaceful American ignorance of international terrorism, The Lupus Genetics Conference was held in Oklahoma City, 7 to 9 September, 2001. This special issue of Genes and Immunity contains some of the original contributions first presented at this meeting and otherwise generally presents contributions from the rapidly advancing genetic understanding of lupus. We are grateful that all of the conference participants arrived home safely and that the travel of only one contributor was interrupted by the horrific events of 11 September, 2001. His extra day in Oklahoma before returning to Europe became nearly a week waiting for air travel to resume.

The etiology of lupus in man has a strong genetic component. The hereditary tendency of this disorder powerfully suggests that particular DNA polymorphisms confer risk for lupus by their influence upon the mechanism of disease. The tasks lain before the 'post-genomic' geneticist studying lupus are to identify these polymorphisms, to establish that they do indeed cause the lupus (or an intermediate) phenotype, and to explain their role on the probably many mechanisms of pathogenesis.

That lupus in man is a disease amenable to a genetic explanation is supported by a number of indirect inferences made from specific properties of its familial aggregation. These arguments along with the genes showing genetic association, and the recently established genetic linkages ${ }^{1}$ demonstrate that there is much to know and suggests how much more there is to learn concerning the genetics of lupus. This recently new avenue of investigation, no doubt, will continue well beyond the productive scientific lives of the investigators who gathered in Oklahoma City that calm and cheerful September weekend. The nascent state of lupus genetic knowledge from the perspective of human lupus, as of the conference, is summarized in the first paper. ${ }^{1}$ Herein, we will recap even newer contributions, including those made at the conference and discuss some of the papers in this issue, mostly focused on lupus, though with a short report on Sjögren's syndrome. ${ }^{2}$

Correspondence: JB Harley, MD, PhD, Oklahoma Medical Research Foundation, 825 N.E. 13th Street, Oklahoma City, Oklahoma 73104, USA. E-mail: john-harley@omrf.ouhsc.edu
Chromosomal crossovers provide the foundation upon which genetic insight is constructed. In man, this means that families are required in order to find genetic linkage. In the decade that the modern genomic approach has been being applied to the genetics of lupus, over 1000 multiplex pedigrees have been collected and genotyped, worldwide. The major groups are located in Uppsala, Minneapolis, Los Angeles, and Oklahoma City. Together, six linkages have been established with lupus as the phenotype. Two of these linkages contain the well-known genetic associations in the HLA (6p21) and Fcy (1q23) regions. The remaining four, at $1 \mathrm{q} 41,2 \mathrm{q} 37,4 \mathrm{p} 15$, and $16 q 13$, are at various stages of confirmation and isolation of genetic effects.

Many new linkage results were presented at The Lupus Genetics Conference. Marta Alarcón-Riquelme presented evidence that PD-1 is a potential explanatory candidate gene for the 2q37 linkage. Betty Tsao presented evidence that the 1q23.1 linkage interacted with the 16q13 linkage. Carl Langefeld showed that the combined data from the Oklahoma and Minnesota genome scan studies supported genetic linkage effects at 4p15, 6p21, and 16q13. Chaim Jacob has assembled the only collection of multiplex pedigrees of Mexican-Americans lupus patients in which he finds suggestive evidence for linkage in three regions on chromosome 1 .

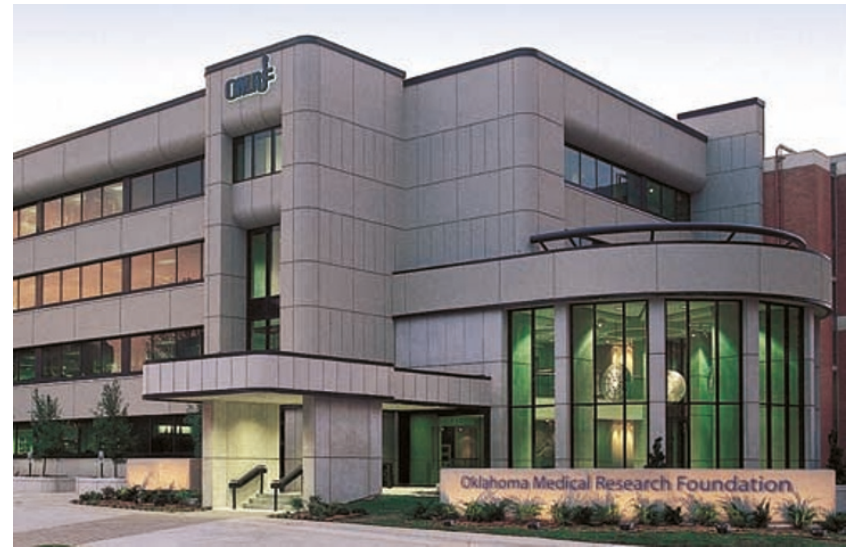

Figure 1 The Oklahoma Medical Research Foundation, site of The Lupus Genetics Conference. 
We do not yet have the technical capacity to perform routine genomic scans for genetic association in outbred populations. Consequently, association studies tend to concentrate upon known susceptibility genes. Jeff Edberg provided additional evidence that the F176 (phenylalanine at amino acid position 176) polymorphism of the FcyIIIA gene was more likely to be responsible for the genetic effect at 1q23 than is the R131 polymorphism of Fc $\gamma$ RIIA. ${ }^{3}$ Their structural studies also continue to help elucidate the genomics of this repetitive and, consequently, complicated region of the genome. ${ }^{4}$ Luminita Pricop and colleagues have shown that polymorphisms in the promoter region of FcyRIIA do not appear to be associated with lupus. ${ }^{5}$

Tim Behrens and the Minnesota group have been using association of ancestral haplotype analysis to study particular HLA haplotypes, especially those related to HLADR3 and HLA-DR2, in an effort to identify the exact polymorphisms that are responsible for these well-known genetic associations with lupus. In their Minnesota collection, there is a strong and convincing linkage signal in the HLA region at 6p21. Pat Gaffney has been applying mRNA expression profiling to the peripheral blood of Minnesota lupus patients and controls and, not surprisingly, finds enormous differences.

In order to take a candidate gene approach for association studies, Lindsey Criswell has been building a large collection of individual affecteds, their parents and controls. She and her colleagues have found association with polymorphisms of FcyRIIIA and the angiotensin converting enzyme. ${ }^{6,7}$ An association with polymorphisms of the B cell marker CD19 are also described in Japanese lupus patients. ${ }^{8}$

Various new or less common methods to address genetic variation were applied to lupus genotyping data from multiplex pedigrees. Jane Olson has modeled genetically complicated phenotypes, such as Alzheimer's disease $^{9}$ and lupus, in various ways. She is one of the only geneticists using principal components analysis to reveal linkages and shows strong linkage signals at 1q22-24, 2q37, 4p16, 4q36, 7p13, 12p12-11, 13p11, 17p13, 17q11-25, and $20 \mathrm{q} 12$ with lupus as published ${ }^{10}$ and as presented herein $^{11}$ (Table 1).

Using another approach, Hal Scofield, ${ }^{12}$ Swapan Nath, Ana Quintero, Amr Sawalha, Jennifer Kelly ${ }^{13}$ and their Oklahoma colleagues presented work stratifying pedigrees by racial background and clinical characteristics (Table 1). ${ }^{14-19}$ In this approach, one assumes that the clinical variation in lupus has either a genetic or environmental (or both) origin. In some situations, sub-grouping pedigrees on the basis of the clinical findings of one (or more) affected(s) in the pedigree will sufficiently increase the genetic homogeneity so that previously unimpressive linkage signals become convincing. Linkages established exceed a LOD of 3.3 at 11q14 with thrombocytopenia, ${ }^{12}$ at 5p15 with multiplex self-reported rheumatoid arthritis, $^{13}$ at 11 p13 with anti-nucleolar antibodies or hemolytic anemia, ${ }^{14,15}$ at 17 p13 with vitiligo, ${ }^{16}$ at $18 \mathrm{q} 21$ and 19 p13 with anti-double stranded DNA antibodies, ${ }^{17}$ and at 2q34-35, 10q22.3, and 11p15.6 with nephritis. ${ }^{18}$ Kaufman et al confirm the 11p13 linkage in pedigrees stratified by thrombocytopenia using polymorphisms within the CD44 gene, which has been an unsuccessful candidate gene for genetic association. ${ }^{19}$

The confidence in linkage improves when an estab- lished linkage becomes significantly more powerful with stratification. For example, stratification on neuropsychiatric criteria for lupus classification substantially improves the evidence for linkage at 4p $16-15 .{ }^{20}$ The appropriate interpretation is not at all clear for linkages detected in the Fcy region of chromosome 1. There is linkage in this region without resorting to stratisfication. So the interpretation of convincing linkages in pedigrees stratified by thrombocytopenia ${ }^{12}$ or hemolytic anemia ${ }^{13}$ (Table 1) is not obvious. The underlying relationships leading to these observations are potentially very complicated and subtle. Nevertheless, which of the 21 genetic effects (Table 1, below, and Table 4 in Kelly et al $^{1}$ ) will be confirmed as the pedigree collections enlarge and exactly how the genes that explain these linkages relate to the clinical and laboratory variations of lupus will be the focus of an enormous investment of effort and resources in the coming years.

Dan Kastner and Mary Claire King brought both an interest in lupus and the experience of having made fundamental contributions to other important genetic problems to the conference. The initial discovery of genetic linkage to breast cancer was made in Professor King's laboratory ${ }^{21}$ and led to the discovery of BRCA1. Indeed, the discovery of linkage in breast cancer is a classic example of the power of pedigree stratification to reveal genetic effects. Unfortunately and despite an enormous effort, only a small number of known breast cancer genetic effects have led to gene identification. When the history of lupus genetics is finally written, hopefully, the effort will lead to much more fundamental and incisive biological insight than has been obtained, relative to the effort and energy dedicated to breast cancer.

Dan Kastner led the group that demonstrated that mutations in the pyrin gene explained familial Mediterranean fever ${ }^{22}$ and has had recent success with other periodic fever phenotypes. ${ }^{23}$ Those explained to this point are single gene defects and provide a perspective from which to contrast the genetic complexity of lupus. Clearly, the therapeutic efficacy and immediate application of TNF- $\alpha$ blockade in patients with a defect in the TNF- $\alpha$ receptor demonstrate how rapidly it is possible for both new genetic insight and therapeutic application to occur. We can only hope that the investigators studying the genetics of lupus will meet with similar spectacular success.

Meanwhile, work in the mouse lupus models is progressing rapidly. Discoveries such as mutations in the fas gene responsible for the $l p r$ defect that causes lupus in MRL mice ${ }^{24}$ have spawned a host of inquiries and have helped formulate our current appreciation of the role of apoptosis in fundamental biology and in the pathogenesis of lupus. Certainly, discoveries in the mouse can be rapidly evaluated in man, and the mouse provides a much more controlled experimental setting in which to evaluate biological mechanisms. Recently, much progress has come from groups working with the classic NZB/NZM lupus model (or its recombinant inbred derivative NZM 2410). Chandra Mohan and Ward Wakeland presented data showing their progress with the NZM phenotype, from which a number of very useful and informative congenics have been generated, especially those showing the incredible complexity of the sle1 effect on mouse chromosome $4 .^{25}$ Indeed, sle $1 b$ has been isolated to a small set of repetitive genes in the 
Table 1 Linkages to systemic lupus erythematosus obtained by principal component analysis (PrC) or pedigree stratification (PeS) of the Oklahoma multiplex pedigree collection

\begin{tabular}{|c|c|c|c|c|c|c|c|c|}
\hline Region & {$[c M]^{\mathrm{a}}$} & Method & $(r e f)^{\mathrm{b}}$ & Probability or LOD & vith model & \multicolumn{2}{|c|}{ Population $\{\text { no. peds }\}^{\mathrm{d}}$} & Criterion or variables ${ }^{\mathrm{e}}$ \\
\hline $1 q 23$ & {$[180]^{\mathrm{f}}$} & PeS & $(12)$ & 3.65 & R100 & All & $\{38\}$ & Thrombocytopenia \\
\hline $1 \mathrm{q} 23$ & {$[184]^{\mathrm{f}}$} & $\mathrm{PeS}$ & $(12)$ & 3.71 & & AA & $\{13\}$ & Thrombocytopenia ${ }^{\mathrm{h}}$ \\
\hline $1 \mathrm{q} 22-24$ & {$[190]^{\mathrm{f}}$} & $\operatorname{PrC}$ & $(11)$ & 4.41 & & All & $\{160\}$ & Male affected; Race $^{\mathrm{h}}$ \\
\hline $1 \mathrm{q} 24$ & {$[200]^{\mathrm{f}}$} & PeS & (13) & 4.0 & & EA & $\{17\}$ & Hemolytic anemia ${ }^{\mathrm{h}}$ \\
\hline $2 q 34-35$ & [238] & PeS & (17) & $P=0.000001$ & & AA & $\{40\}$ & Nephritis (SLEN2) ${ }^{\mathrm{h}}$ \\
\hline $2 q 37$ & {$[267]^{\mathrm{f}}$} & $\operatorname{PrC}$ & (11) & 4.1 & & All & $\{160\}$ & Race; Neuropsychiatric ${ }^{\text {h }}$ \\
\hline 4p16-15 & {$[3]^{\mathrm{f}}$} & PrC & $(11)$ & 4.23 & & All & $\{160\}$ & PrC no. 6 from reference $11^{\mathrm{h}}$ \\
\hline 4p16-15 & {$[3]^{\mathrm{f}}$} & PeS & (19) & 5.12 & $\mathrm{D} \sim 80$ & EA & $\{23\}$ & Neuropsychiatric (SLEB3)g,h \\
\hline $4 q 36.1$ & [208] & PrC & $(10)$ & $P=0.00007$ & & All & $\{126\}$ & PrC no. 3 from reference $10^{\mathrm{h}}$ \\
\hline 5p15.3 & [14] & PeS & $(\mathrm{b})$ & 6.9 & & EA & $\{14\}$ & Rheumatoid arthritis (SLER1)g,h \\
\hline $7 \mathrm{p} 13$ & [69] & PrC & $(10)$ & $P=0.0001$ & & All & $\{126\}$ & $9 \operatorname{PrC}(\text { especially, malar rash })^{\mathrm{h}}$ \\
\hline $10 \mathrm{q} 22.3$ & [38] & PeS & (17) & $P=0.0000008$ & & EA & $\{31\}$ & Nephritis $\left(\right.$ SLEN1) ${ }^{\mathrm{h}}$ \\
\hline $11 \mathrm{p} 15.5$ & {$[2]$} & PeS & (17) & 3.34 & $\mathrm{R} 49 / 92$ & AA & $\{20\}$ & Nephritis (SLEN3) ${ }^{\mathrm{h}}$ \\
\hline $11 \mathrm{p} 13$ & [46] & PeS & (12) & 4.60 & D39/99 & AA & $\{13\}$ & Thrombocytopenia (SLET1)g,h \\
\hline $11 \mathrm{q} 14$ & [82] & PeS & (13) & 4.70 & D35/99 & AA & $\{16\}$ & Hemolytic anemia (SLEH1)g,h \\
\hline $11 \mathrm{q} 14$ & {$[82]$} & PeS & $(14)$ & 5.62 & D95/99 & AA & $\{11\}$ & Nucleolar ANA (SLEH1)g,h \\
\hline 12 p12-11 & [38] & $\operatorname{PrC}$ & $(11)$ & 3.98 & & All & $\{160\}$ & Oral ulcers and photosensitivity ${ }^{\mathrm{g}}$ \\
\hline $13 \mathrm{p} 11$ & [10] & $\operatorname{PrC}$ & (11) & 3.12 & & All & $\{160\}$ & PrC no. 4 from reference $11^{\mathrm{g}}$ \\
\hline $17 \mathrm{p} 13$ & {$[23]$} & PeS & (15) & 3.64 & R16 & EA & $\{16\}$ & Vitiligo $($ SLEV1)g \\
\hline $17 \mathrm{p} 13$ & {$[23]$} & $\operatorname{PrC}$ & $(11)$ & 4.41 & & All & $\{160\}$ & Age of onset ${ }^{g}$ \\
\hline $17 q 11-25$ & [110] & $\operatorname{PrC}$ & (11) & 2.86 & & All & $\{160\}$ & Race; Serositis; Neuropsychiatric ${ }^{g}$ \\
\hline $18 \mathrm{q} 21$ & [65] & PeS & (16) & 3.40 & R100 & AA & $\{29\}$ & Anti-dsDNA (SLED2)g \\
\hline $19 \mathrm{p} 13$ & {$[42]$} & PeS & $(16)$ & 4.93 & D49/92 & EA & $\{37\}$ & Anti-dsDNA (SLED1)g \\
\hline 20p12-q12 & {$[45]$} & $\operatorname{PrC}$ & $(11)$ & 5.55 & & All & $\{160\}$ & PrC no. 2 from reference $11^{\mathrm{g}}$ \\
\hline
\end{tabular}

${ }^{\mathrm{a}} \mathrm{Genetic}$ distance in $\mathrm{cM}$ from the $\mathrm{p}$ telomere is given in brackets.

bPedigree stratification (PeS) results with $\mathrm{LOD} \geqslant 3.3$ or $P \leqslant 0.00002$ and principal component (PrC) results with $P \leqslant 0.0001$ are presented. Principal components are evaluated by SIBPAL2 in sibpairs from 126 pedigrees ${ }^{10}$ or in affected relative pairs from 160 pedigrees by LODPAL. ${ }^{11}$

'Linkage to nephritis was established using SIBPAL2, therefore these are expressed as $P$ values, rather than LOD scores. The model producing the given LOD score is given where $\mathrm{R}$ and $\mathrm{D}$ indicate recessive and dominant and the numbers indicate the penetrance, and by male and female when two different values are given. If a model is not indicated, then the non-parametric result is presented.

${ }^{\mathrm{d}}$ African-American (AA), European-American (EA), or All pedigrees evaluated. The number of pedigrees producing the result is indicated \{\}. 'The stratification criterion or variables used are presented followed by the name of the genetic linkage effect in parentheses, when available. ${ }^{\mathrm{f}}$ Regions where linkage has, respectively, been established in the Oklahoma (1q23 and 4p16-15) and Uppsula (2q37) pedigree collections multiplex for lupus are indicated (see Table 4 of Kelly et $a l^{1}$ ).

gFine mapping has been done and supports the presence of the linkage effect.

${ }^{\mathrm{h}}$ Multipoint analysis supports linkage.

CD48 family and data supporting sle1c being CR2 gene was presented by Susan Boackle and Michael Holers. ${ }^{26}$ Dr Mohan has concentrated upon defining the immune mechanisms by focusing upon various intermediate phenotypes. The contribution from his laboratory to this issue is an example of this work. ${ }^{27}$ Brian Kotzin shared his evidence for Ifi202 as the explanatory gene for the nba2 linkage. ${ }^{28}$ Dwight Kono has shown that mercuryinduced autoimmunity maps to mouse chromosome 1 at a locus now referred to as $H m r 1 .{ }^{29}$ Approaching lupus in animals from a different vantage point, Judith James has shown that B cell epitope spreading in the peptideinduced model of anti-Sm lupus in normal mice is genetically determined ${ }^{30,31}$ and that AKRXC57L/J recombinant inbred strains map this effect to the top of mouse chromosome 4 with dominant inheritance.

All of the data available are consistent with lupus having richly complicated genetic explanations, in both man and mouse. Indeed, the obvious complexity in the mouse should give us pause to be concerned that the genetic situation in man would be so complicated that progress would be impossible. Fortunately, actual experience and the initial successes in trying to define genetic effects in human lupus have partially allayed these fears. Clearly in man, there must be many genes contributing to the lupus phenotype.
In addition, we also now know enough to conclude that in human lupus there is no single dominating gene; no gene plays a role like HLA-DR does in type 1 diabetes where more than half of the genetic variance is found at HLA. Whether there are 10 or a thousand genes involved, however, is less important to know than how they operate to generate the phenotype. This is the knowledge that promises to empower the medical research community in academia and industry to defeat this disease.

All of the participants in the conference are grateful to the patients and their family members who provide materials to study. We are thankful for the financial support from sources public and private that make this enterprise possible. We are grateful to the Oklahoma Medical Research Foundation and Amgen corporation for financial support of The Lupus Genetics Conference and to Joan Leaver and Peggy Anderson for their organizational and administrative assistance which made the conference a success. Finally, we appreciate our colleagues around the world who toil to understand the genetics of lupus and others who have developed methods and technologies that have made the genetics of lupus a problem with solutions.

John Harley Oklahoma City June, 2002 


\section{References}

1 Kelly JA, Moser KL, Harley JB. The genetics of systemic lupus erythematosus: Putting the pieces together. Genes Immun 2002; 3 (Suppl 1): S71-S85.

2 Downie-Doyle S, Lester S, Bardy P, Gordon T, Rischmueller M, Pile K. Immunoglobulin kappa light chain gene alleles are not associated with primary Sjogren's syndrome. Genes Immun 2002; 3 (Suppl 1): S63-S65.

3 Edberg JC, Langefeld CD, Wu J et al. Genetic linkage and association of Fc $\gamma$ receptor IIIA (CD16A) on chromosome 1q23 with human systemic lupus erythematosus. Arthritis Rheum 2002; (in press).

4 Su K, Wu J, Edberg JC, McKenzie SE, Kimberly RP. Genomic organization of classical human low-affinity Fcy receptor genes. Genes Immun 2002; 3 (Suppl 1): S51-S56.

5 Pricop L, Li L, Salmon JE, Jacob CO. Characterization of the Fc $\gamma$ RIIA promoter and 5'UTR sequences in patients with systemic lupus erythematosus. Genes Immun 2002; 3 (Suppl 1): S47-S50.

6 Seligman VA, Suarez C, Lum R et al. The Fcy receptor IIIA-158F allele is a major risk factor for the development of lupus nephritis among Caucasians but not non-Caucasians. Arthritis Rheum 2001; 44: 618-625.

7 Parsa A, Peden E, Lum RF et al. Association of angiotensin converting enzyme polymorphisms with systemic lupus erythematosus: analysis of 811 SLE families. Genes Immun 2002; 3 (Suppl 1): S42-S46.

8 Kuroki K, Tsuchiya N, Tsao BP et al. Polymorphisms of human CD19 gene: possible association with susceptibility to systemic lupus erythematosus in Japanese. Genes Immun 2002; 3 (Suppl 1): S21-S30.

9 Olson JM, Goddard KA, Dudek DM. A second locus for verylate onset Alzheimer Disease: a genome scan reveals linkage to $20 \mathrm{p}$ and epistasis between $20 \mathrm{p}$ and the amyloid precursor protein region. Am J Hum Genet 2002; 71: 154-161.

10 Rao S, Olson JM, Moser KL et al. Linkage analysis of human systemic lupus erythematosus-related traits: a principal component approach. Arthritis Rheum. 2001; 44: 2807-2818.

11 Olson JM, Song Y, Dudek DM et al. A genome screen of systemic lupus erythematosus using affected-relative-pair linkage analysis with covariates demonstrates genetic heterogeneity. Genes Immun 2002; 3 (Suppl 1): S5-S12.

12 Scofield RH, Bruner GR, Kelly JA et al. Thrombocytopenia identifies a severe familial phenotype of systemic lupus erythematosus and reveals genetic linkages at 1q21 and 11p13. Blood 2002; (in press).

13 Namjou B, Nath SK, Kilpatrick J et al. Stratification of pedigrees multiplex for systemic lupus erythematosus (SLE) and for selfreported rheumatoid arthritis defects on SLE susceptibility gene (SLER1) at 5p13.3. Arthritis Rheum 2002; (in press).

14 Kelly JA, Thompson K, Kilpatrick J et al. Evidence for a susceptibility gene (SLEH1) on chromosome 11q14 for systemic lupus erythematosus (SLE) families with hemolytic anemia. PNAS 2002; (in press).

15 Sawalha AH, Namjou B, Nath SK et al. Genetic linkage of systemic lupus erythematosus with chromosome 11q14 (SLEH1) in African-American families stratified by a nucleolar antinuclear antibody pattern. Genes Immun 2002; 3 (Suppl 1): S31-S34.
16 Nath SK, Kelly JA, Namjou B et al. Evidence for a susceptibility gene, SLEV1, on chromosome $17 \mathrm{p} 13$ in families with vitiligorelated systemic lupus erythematosus. Am J Hum Genet 2002; 69: 1401-1406.

17 Namjou B, Nath SK, Kilpatrick J et al. Genome scan stratified by anti-double stranded DNA (dsDNA) autoantibody in pedigrees multiplex for systemic lupus erythematosus (SLE) establishes linkages at 19p13.2 (SLED1) and 18q21.1 (SLED2). Genes Immun 2002; 3 (Suppl 1): S35-S41.

18 Quintero-Del-Rio AI, Kelly JA, Kilpatrick J, James JA, Harley JB. The genetics systemic lupus erythematosus stratified by renal disease: linkage at10q22.3 (SLEN1), 2q34-35 (SLEN2) and 11p15.6 (SLEN3). Genes Immun 2002; 3 (Suppl 1): S57-S62.

19 Kaufman KM, Rankin J, Harley ITW, Kelly JA, Harley JB, Scofield RH. A genetic marker within the CD44 gene confirms linkage at 11p13 in African-American families with lupus stratified by thromboxcytopenia, but genetic association with CD44 is not present. Genes Immun 2002; 3 (Suppl 1): S86-S88.

20 Nath SK, Kelly JA, Reid J et al. SLEB3 in systemic lupus erythematosus (SLE) is strongly related to SLE families ascertained through neuropsychiatric manifestations. Hum Genet 2002; 111: $54-58$.

21 Hall JM, Lee MK, Newman B et al. Linkage of early-onset familial breast cancer to chromosome 17q21. Science 1990; 250: 1684-1699.

22 The International FMF Consortium. Ancient missense mutations in a new member of the RoRet gene family are likely to cause familial Mediterranean fever. Cell 1997; 90: 797-807.

23 Aksentijevich I, Galon J, Soares $M$ et al. The tumor-necrosis factor receptor-associated periodic syndrome: new mutations in TNFRSF1A, ancestral origins, genotype-phenotype studies, and evidence for further genetic heterogeneity of periodic fevers. Am J Hum Genet 2001; 69: 301-314.

24 Watanabe-Fukunaga R, Brannan CI, Copeland NG, Jenkins NA, Nagata S. Lymphoproliferation disorder in mice explained by defects in Fas antigen that mediates apoptosis. Nature 1992; 356: 314-317.

25 Morel L, Blenman KR, Croker BP, Wakeland EK. The major murine systemic lupus erythematosus susceptibility locus, Sle1, is a cluster of functionally related genes. Proc Natl Acad Sci USA 2001; 98: 1787-1792.

26 Boackle SA, Holers VM, Chen X et al. Cr2, a candidate gene in the murine Sle1c lupus susceptibility locus, encodes dysfunctional protein. Immunity 2001; 15: 775-785.

27 Xie S, Chang S, Sedrak P, Kaliyaperumal A, Datta SK, Mohan C. Dominant NZB contributions to lupus in the (SWR X NZB) F1 model. Genes Immun 2002; 3 (Suppl 1): S13-S20.

28 Rozzo SJ, Allard JD, Choubey D et al. Evidence for an interferoninducible gene, Ifi202, in the susceptibility to systemic lupus. Immunity 2001; 15: 435-443.

29 Kono DH, Park MS, Szydlik A et al. Resistance to xenobioticinduced autoimmunity maps to chromosome 1. J Immunol 2001; 167: 2396-2403.

30 James JA, Harley JB. B-cell epitope spreading in autoimmunity. Immunol Rev 1998; 164: 185-200.

31 James JA, Harley JB. A model of peptide-induced lupus autoimmune B cell epitope spreading is strain specific and is not $\mathrm{H}$ 2 restricted in mice. J Immunol 1998; 160: 502-508. 